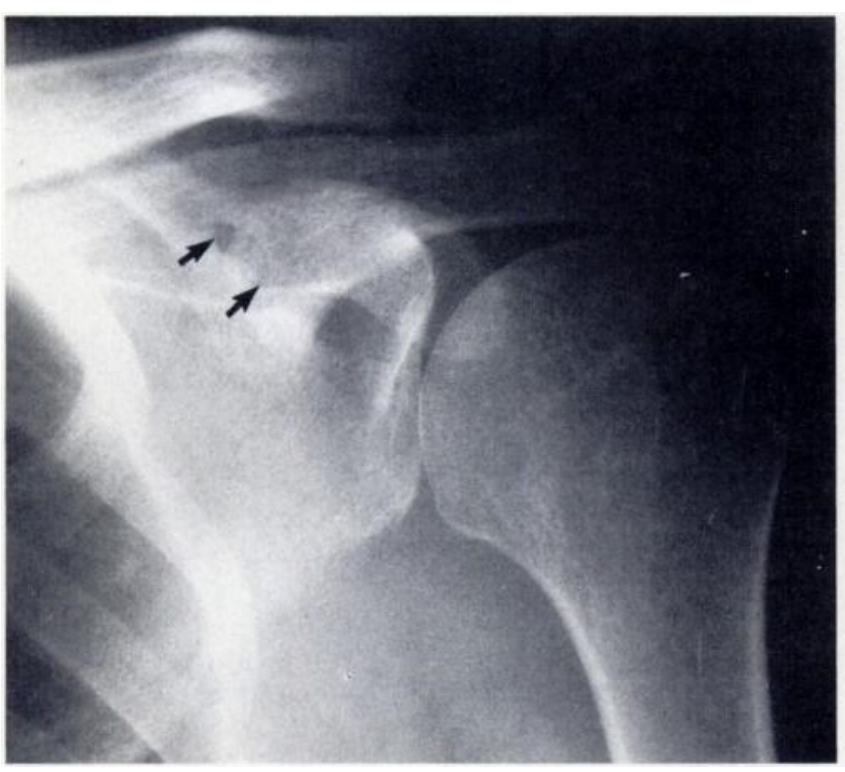

Fig. 2

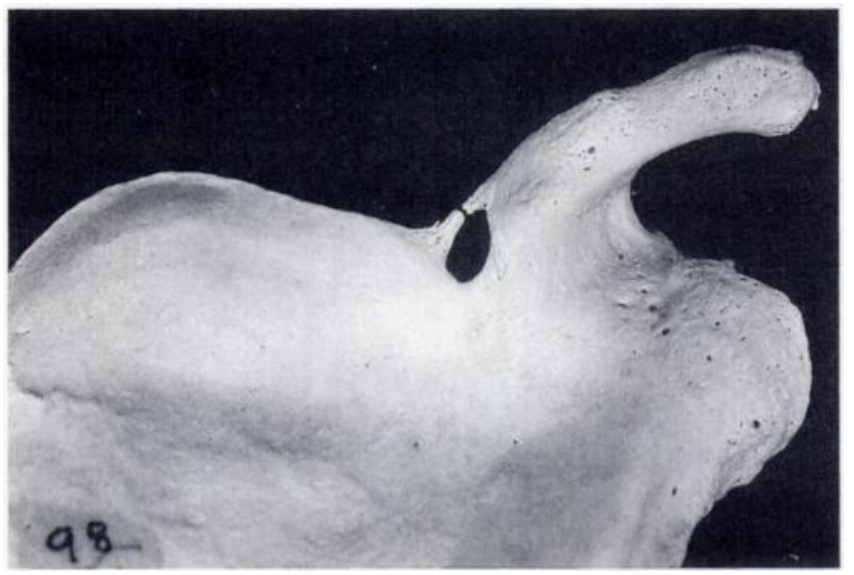

Fig. 3 scapular notch has been described in the anthropological (Graves 1921; Hrdlicka 1942a,b) and occasionally in the surgical literature (Rengachary et al 1979), ranging from an absence of the notch through a capacious anthropoid type to a progressively smaller more constricted opening which may be bridged. The frequency of occurrence of these alterations is uncertain and varies in different population groups. The open, anthropoid-like, contour is much more common among the Eskimo whereas the bony bridge is found more in Caucasian males (Hrdlicka 1942a). Bony bridges are seen more often with increasing age suggesting that they may be related to enthesopathic changes (Hrdlicka 1942a). Their presence may be associated with a predilection to a traction-type injury of the suprascapular nerve (Rengachary et al 1979).

I sincerely appreciate the encouragement and support of Dr Joseph Zuckerman. Chief of Staff and of Orthopedic Surgery. the Hospital of Joint Diseases, New York. I also thank Dr David R. Hunt of the Department of Anthropology. Smithsonian Institute, Washington. Jaymie L. Brauer. Department of Anthropology. American Museum of Natural History, New York, for their invaluable assistance in examining their museum collections, Frank Martucci for his superb photographic work and Hadas Sasson for her technical assistance.

No benefits in any form have been received or will be received from a commercial party related directly or indirectly to the subject of this article.

\section{REFERENCES}

Graves WW. The types of scapulae: a comparative study of some correlated characters in human scapulate. Am J Phys Anthropol 1921;IV:2:111-28.

Hrdlicka A. The scapula: visual observations. Am J Phys Anthropol 1942a:29:73-94.

Hrdlicka A. The adult scapula: additional observations and measurements. Am J Phys Anthropol 1942b;29:363-415.

Rengachary SS, Neff JP, Singer PA, Brackett CE. Suprascapular entrapment neuropathy: a clinical, anatomical and comparative study. Neurosurgen 1979;5:441-6.

\title{
THE MEASUREMENT OF ANGULAR DEFORMITY: AN EXTENDED ROLE FOR THE 'COBBOMETER'
}

\section{T. P. S. BHUllaR, N. M. A. PORTINARO, M. K. D. BENSON}

Progressive acetabular maturation in infancy is best assessed by the acetabular index first described by Hilgen-

T. P. S. Bhullar, FRCS G, FRCS Ed(Orth). Senior Registrar

M. K. D. Benson, FRCS, Consultant Orthopaedic Surgeon

Department of Orthopaedic Surgery, Nuffield Orthopaedic Centre NHS Trust, Windmill Road. Headington, Oxford OX3 7LD. UK.

N. M. A. Portinaro. MD. Research Fellow

Department of Orthopaedic Surgery, San Raffaele Hospital, University of Milan. Via Olgettina 60, Milan, Italy.

Correspondence to Mr T. P. S. Bhullar.

(1)1995 British Editorial Society of Bone and Joint Surgery $0301-620 X / 95 / 3 R 39 \$ 2.00$

J Bone Joint Surg [Br] 1995:77-B:506-7.

Received 23 May 1994; Accepted 5 August 1994 reiner (1925). In a busy clinic, drawing lines on radiographs can be time-consuming and is prone to error. Moreover, defaced radiographs may make subsequent research difficult.

The Cobbometer, previously described for measuring spinal deformity (Whittle and Evans 1979), allows swift, reproducible measurement of angles without marking the films. Its design has been refined and has three basic components: a tough polycarbonate plate; a protractor calibrated from $0^{\circ}$ to $180^{\circ}$ in both directions; and a clear perspex pendulum. The last two are attached to the base plate by a low-friction spindle and are encased in a protective perspex cover. 


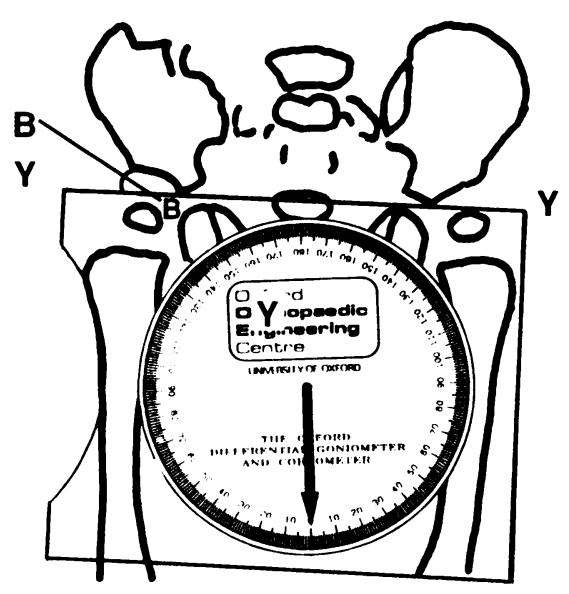

Fig. la

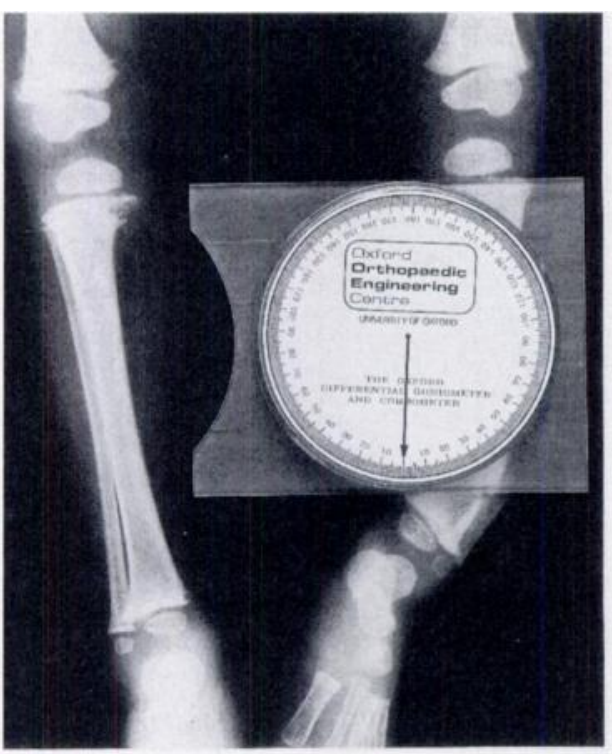

Fig. 2a

Measurement of the angle. The radiograph is anchored firmly on a vertical viewing screen. One of the straight edges of the device is placed on the YY Hilgenreiner line and the protractor is rotated so that the central mark on the free-swinging pendulum is brought to zero (Fig. 1a). The same straight edge of the base plate is then placed along the line BB and the pendulum allowed to come to rest. The angle measured can be read directly from the protractor (Fig. 1b). The latter rotates with the base plate, but the pendulum remains vertical throughout.

Other applications. The same simple principle can be applied to the adult pelvis to measure Sharp's acetabular angle (1961). Graf's (1984) alpha and beta angles which define the inclination of the bony and cartilaginous acetabulum, can also be easily measured on the ultrasound hard copy using this device. Talocalcaneal angles for assessing

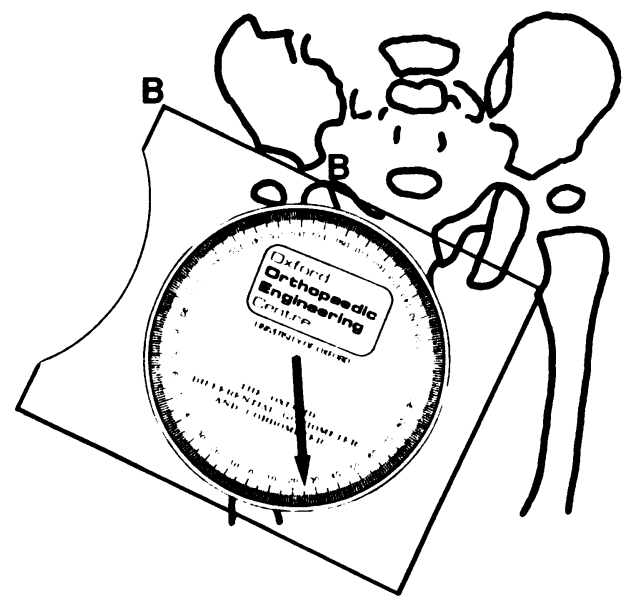

Fig. lb

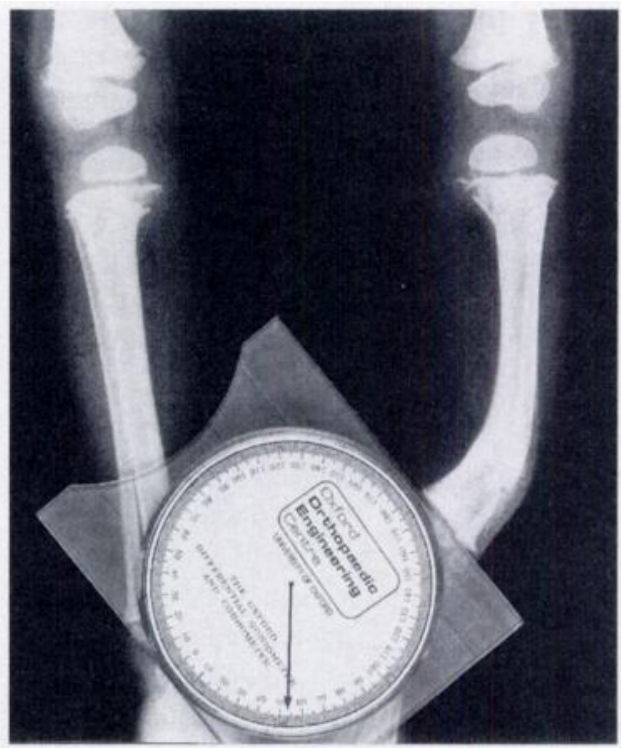

Fig. 2b

club foot are readily measured as is the angular deformity in long bones. Parallel alignment of proximal and distal bone ends or epiphyseal plates is easily and precisely assessed. Figure 2 shows angular tibial malalignment in a child with metaphyseal dysplasia.

No benefits in any form have been received or will be received from a commercial party related directly or indirectly to the subject of this article.

\section{REFERENCES}

Graf R. Fundamentals of sonographic diagnosis of infant hip dysplasia. $J$ Pediatr Orthop 1984:4:735-4().

Hilgenreiner $\mathbf{H}$. Zur fruhdiagnose und fruhbehandlung der angeboronen huftgelenkeverrenkung. Med Klin 1925:21:1385-425.

Sharp IK. Acetabular dysplasia: the acetabular angle. J Bone Joint Surg [Br/ 1961:43-B:268-72.

Whittle MW, Evans M. Instrument for measuring the Cobb angle in scoliosis. Lancet 1979:1:414. 